\title{
ESCOLAS DE SAMBA
}

Ricardo Cravo Albin

O texto traça uma história das escolas de samba cariocas, buscando estabelecer uma linha de continuidade entre o evento contemporâneo e as diversas festas processionais características da cidade do Rio de Janeiro, bem como com as manifestações rítmicas dos primeiros carnavais.

ESCOLAS DE SAMBA, CARNAVAL, RIO DE JANEIRO. 
Há 20 anos, o grupo especial das escolas de samba já fazia um show arrebatador, em marcha para o apogeu que logo chegaria na década seguinte. Os camarotes e frisas, naquela altura, ainda ficavam a desejar e não ostentavam nem de longe a suntuosidade e o brilho (até provocador) de hoje em dia. ${ }^{1}$

Meu caro, estou estupefato com a grandeza e com as possibilidades de interpretação desse desfile que acabo de ver. E lhe digo: um povo que se organiza desse jeito, em número assombroso de quase cinquenta mil pessoas aquarteladas em dezenas de escolas, será um povo com potencialidade infinita de construir um grande país. Um raro país organizado a partir do canto, da dança, da sensualidade. Do desejo ancestral do homem em busca da felicidade.

Mais ou menos com essas palavras, depois da Mangueira passar por volta de onze da manhã, um dos dois professores da Sorbonne que eu acompanhava se referiu ao desfile de 1986. Enquanto ouvia deliciado o comentário, devorava com eles médias com pão num pé-sujo do Edifício Balança Mas Não Cai, nas imediações do Sambódromo Darcy Ribeiro. Foi o próprio Darcy, cujo nome ainda não titularizava o Sambódromo, quem me pedira para levar seus dois colegas franceses ao desfile.

Naquela hora que se aproximava do almoço, num calor infernal do alto verão carioca, meus dois acompanhantes e eu tomávamos um prosaico café da manhã, em meio à multidão surreal de desfilantes em busca de táxis, ônibus ou trens. Portando alegorias de cabeça, às mãos, exaustos mas felizes, milhares de homens e mulheres das duas escolas grandes que acabavam de desfilar, Mangueira e Portela, misturavam o verde-rosa com o azul-e-branco, num bulício surreal que se constituía em outro espetáculo à parte. Os dois franceses, homens pequenos, muito magros, brancos e de óculos, mal acreditavam no que viam. Aquela mistura anárquica era a antítese da organização a que eles tinham acabado de assistir das arquibancadas.

Mas como, perguntavam-me os dois abismados interlocutores, esse desfile espontâneo, milionário, em que cada um paga sua fantasia, no qual os participantes nada ganham para se exibir, chegou a esse estágio de irradiação de beleza e de ordem quase militar? Respondi-lhes demoradamente. Apesar do cansaço. Apesar da hora. Apesar do calor - embora o desfile tivesse sido aberto com chuva torrencial pela Beija-Flor, que, milagre de resistência, passou incólume, como se caíssem do céu apenas papel-picado, amáveis fragmentos de confete. E não um toró de assustar.

\section{AS ORIGENS}

O carnaval carioca seria muito influenciado em suas origens mais remotas por festas de igrejas como as da Glória, da Penha, da Matriz e por procissões religiosas, como as de São Jorge, santo de destacada preferência popular, ou mesmo pelas folias do Divino e até pelos congos de origem africana. Alguns estudiosos entendem que o primeiro desfile carnavalesco se deu em pleno centro histórico do Rio, na Rua Direita (hoje Primeiro de Março), para comemorar a subida ao trono português de El-Rei Dom João V ao comecinho de 1707. A Corte portuguesa era uzeira e vezeira em comemorar com passeatas, des- 
files e muita bebedeira acontecimentos como nascimentos, batizados, ou casamentos de seus integrantes, bem como a chegada à cidade de grandes vultos políticos.

Os festejos duravam, quase sempre, até três dias (daí o futuro tríduo momesco) e tinham como características principais uma cenografia específica para cada um dos eventos a ser celebrado. Tanto que arcos e obeliscos eram erguidos, galhardetes e luminárias eram distribuídos por praças, pelas ruas, em frente às igrejas, centro natural de qualquer movimento que envolvesse pequenas ou grandes multidões.

Ora, todos esses elementos de origens tão diversificadas, quando reunidos num futuro, só poderiam resultar em folguedos de proporções monumentais, acimentados no cadinho da mistura das tradições europeias, africanas e indígenas, mistura que de tão criativa chega a ser até despudorada.

Aliás, a forma de cortejo, que a escola de samba levou a uma consequência galvanizadora, vem da religião católica e de suas festas processionais. Tradição fundada na esteira de séculos ou até milênios. A forma da escola de samba é, portanto, muito mais a de uma procissão que a de uma ópera popular, como foi impropriamente chamada. Até porque a escola de samba flui pela rua ao som de música única,enquanto a ópera se desenvolve em palco fixo ao som de músicas várias.

Muitos dizem que escolas de samba tem um coração. A origem do coração da escola de samba, que é como em geral os críticos chamam a bateria percussiva, vem de outra tradição primicial e que tomou no Rio o nome de "Zé Pereira", isso lá por volta de 1850. Era um conjunto de bumbos criado pelo sapateiro português José Paredes, nome cuja corruptela acabou por virar o Zé Pereira e que inaugurou uma forma de carnaval organizado no Rio, capital do Império. O entrudo, diversão grosseira e abusiva da maioria do povo das ruas, se contrapunha aos bailes de máscaras a que só as classes mais privilegiadas ascendiam. Fora do entrudo e longe dos bailes, os blocos de zé-pereiras logo seriam uma outra possibilidade de brincar o carnaval ao som apenas de percussão. Elemento de essência que viria a ser agregado às escolas de samba ao começo da década de 30 do século passado.

Quanto à forma processional de desfile orgânico por uma determinada rua, as escolas têm suas origens mais diretas nos ranchos carnavalescos e nas grandes sociedades. Essas, anteriormente chamadas de grandes clubes carnavalescos, foram pioneiras na "organização" do carnaval, com sede própria, estatutos e funcionando quase todo o ano com bailes, convescotes e que tais. Elas promoviam no carnaval desfiles pela Rua do Ouvidor (Rio) nas últimas décadas do século XIX que agregavam temas, idéias ou críticas sociais e políticas. As grandes sociedades (especialmente as três mais famosas, Tenentes do Diabo, Fenianos e Democráticos) contribuíram para causas generosas da época, como a abolicionista, a republicana ou a defesa do trabalhador. Elas não inspirariam a formação das escolas apenas nos temas do desfile (o enredo de hoje) ou na organização administrativa (sede própria, estatutos e diretorias com dirigentes diversificados). Foram também responsáveis por uma das essências do desfile das escolas: os carros alegóricos, forma imbatível de exibir o enredo para muito além do binômio canto e dança. Alguns dos 
carros alegóricos das grandes sociedades foram, segundo observadores insuspeitos como Lima Barreto, João do Rio ou Marques Rebello, verdadeiras obras de arte, produzidas por cenógrafos e maquinistas de teatro. Tal como nas escolas de samba a partir dos anos 1960, quando gente de teatro do porte de Fernando Pamplona e Arlindo Rodrigues abriu novos campos estéticos para as alegorias e para os carros, que culminariam no desabrochar de carnavalescos criativos e audaciosos como João Trinta, Fernando Pinto, Rosa Magalhães, Max Lopes, Renato Lage e até mesmo Paulo Barros. Este último provocando a inovação arrojada (já no século XXI) dos carros alegóricos montados em cima da coreografia de dezenas de desfilantes.

Não tenho dúvida que, quanto à estrutura e origens sociais do desfile, as escolas beberiam muito mais da segunda novidade do carnaval carioca logo depois das grandes sociedades, nascidas a partir da classe média e dos intelectuais, e que foram os ranchos. Estes tiveram origens ainda mais populares, incorporando tradições típicas do dia de Reis e de procissões religiosas. Seu criador foi o negro baiano Hilário Jovino Ferreira. Estruturado na Pedra do Sal, próxima ao cais do porto do Rio, o primeiro rancho "Rei de Ouros" jamais alcançaria no final do século XIX a notoriedade das Grandes Sociedades, acolitadas pela imprensa e por intelectuais de renome. Situação que só seria mudada a partir da chegada do rancho Ameno Resedá em 1908, quando seus criadores inovaram pra valer: saíam com um tema único, distribuídos em alas específicas. Desse modo, o Rancho já desfilava com muitas das estruturas que as Escolas agregariam, a começar pelo abre-alas (com a tradicional saudação à imprensa e portando o nome do rancho). A que se seguia a comissão de frente - formada pela diretoria, tal como nas Escolas de Samba ainda há duas dezenas de anos. Nos ranchos os desfilantes cantavam e dançavam sob um comando único, o mestre de manobra, que era, sem tirar nem pôr, o essencial diretor de harmonia das escolas. Aliás, entre os mais célebres e temidos - até porque na hora agá da escola pisar na avenida eles eram reis absolutistas - estão Xangô da Mangueira, Aniceto, do Império e Laíla, do Salgueiro.

A bandeira do Rancho era garbosamente conduzida pela porta-estandarte, que se fazia acompanhar pelo baliza, encarregado de cortejá-la, girando em torno dela: são hoje a porta-bandeira e o mestre-sala das Escolas, possivelmente o mais belo, o mais criativo e mais emocionante fragmento do superdesfile.

\section{O QUE SÃO AS ESCOLAS DE SAMBA}

Para mais adequadamente se saber o que o que as escolas de samba significam, torna-se fundamental a percepção do que seja paixão, visceralidade, relação carnal, gozo.

Como não confrontar esses sentimentos de culminância ante uma agremiação carnavalesca à qual todos afluem: 1 . espontaneamente; 2 . pagando fantasias quase sempre acima das suas posses; 3 . submetendo-se a rígidas e por vezes severas, quando não até penosas, normas de prévios ensaios, além da concentração para o desfile, que chega a custar horas a fio. E o mais cativante: toda a tensão e sofrimentos impostos se liberam durante apenas oitenta minutos - o tempo em que a Escola hoje desfila da cabeceira da 
pista à zona da dispersão. Essa fração de uma hora e vinte minutos em que mais de três mil pessoas (podendo ir até o dobro) se interagem em comunidade e dentro de um sistema nuclear muito rígido e organizado, é um tempo mágico, cheio de interpretações sociológicas, políticas e sociais. Porque a comunidade deve atuar com um só coração, projetando para a platéia uma rigorosa unidade de canto e dança simultâneos.

Popular desde suas origens no começo da década de trinta, ela se poria de pé com integrantes das camadas mais baixas da estrutura social carioca. Era aquela gente mulata ou negra, sem profissão definida, que veio para o Rio como veteranos livres da Guerra do Paraguai ou aqueles que chegavam à Capital Federal vindos do êxodo das fazendas de café, quando a Princesa Isabel aboliu a escravidão em 1888. Ou mesmo alguns remanescentes da epopeia de Canudos de Antônio Conselheiro na Bahia. A maioria acabaria por ocupar as encostas verdejantes do Rio, inaugurando as favelas

O local de nascimento da escola de samba foi o centro do Rio, ao sopé do Morro de São Carlos na Cidade Nova e no Estácio de Sá - vizinhos à Lapa boêmia e à Praça XI antiga, celeiros de sambas e de bambas.

Um grupo de negros e mulatos boêmios que viviam de pequenos biscates dedicava-se com fervor ao violão, ao pandeiro, a fazer batucadas. Ou a fazer... absolutamente nada. Quando não, rodas de samba, gênero que nascera não tinha nem dez anos. Ismael Silva, autor da maravilha que é Se você jurar (com Nilton Bastos) e co-autor de doze pepitas com Noel Rosa, liderava o grupo a que se somavam malandros históricos como Brancura e compositores não menos importantes como a dupla Bide e Marçal (do clássico Agora é cinza). O próprio Ismael (com quem convivi meses a fio ao Ihe escrever o show autobiográfico Se você jurar) me disse que o termo "escola de samba" foi inventado por ele devido a três razões. A primeira - e a menos importante -, porque a turma do Estácio se reunia quase em frente à Escola Normal, situada na esquina da rua Machado Coelho com a rua Joaquim Palhares. A segunda razão - de importância bem maior -, era o fato de, ao se intitularem de escola de samba, deferiam a si mesmos a graduação de bambas, de mestres, de professores na arte de produzir sambas. O terceiro motivo o mais importante de todos -, era que o termo Escola de Samba qualificaria uma possível melhoria e ascendência em relação aos demais blocos carnavalescos, seus concorrentes. Ismael ainda chamaria a atenção para o fato de que ele intitulou o seu bloco, já portando o nome de escola de samba, de "Deixa falar". Como se previsse críticas dos outros blocos, alguns dos quais bem conceituados como o "Fiquei Firme" (do morro da Favela), o "Vai-como-pode" (de Oswaldo Cruz, depois a Escola de Samba Portela, mas só a partir de 1935) e o "Arengueiro" (da região do morro da Mangueira, depois a Estação Primeira da Mangueira).

Claro que os desafiantes do Estácio tinham a intenção de fazer algo melhor que os demais concorrentes. Mas a intenção logo, logo, se esvairia, porque sua turma, segundo o doce Ismael me confidenciaria em espichadas conversas, era mesmo de fritar bolinhos... Eles queriam fazer samba, namorar, cantar. Viver a vida boêmia, enfim, mas sem a responsabilidade incômoda de ter que suar camisa para a "Escola de Samba Deixa Fa- 
lar" derrotar as concorrentes. Até porque em seus três desfiles públicos (29, 30 e 31), a "Deixa Falar" não exibiu as novidades que qualificariam logo depois as futuras escolas de samba. Uma vantagem eles tinham: os sambas que cantavam eram perfeitas jóias da música carioca como Se você jurar, que (e aí vai um segredinho soprado pelo Ismael - foi quase todo feito por Nilton Bastos, mas acabado por ele) teria sido cantado no desfile de 30 e, logo que gravado por Chico Alves e Mário Reis, também na derradeira aparição da “Deixa Falar", em 1931.

Foi sair de cena a pioneira agremiação carnavalesca de Ismael Silva e sua Turma do Estácio, para as escolas de samba, aí sim, instalarem-se de vez. Muitos dos blocos vestiram o novo nome e as inovações começaram a se fazer sentir. Inicialmente, as escolas se apresentavam na Praça XI, uma das catedrais mais estimadas dos folguedos dos negros no Rio, inclusive de onde saíram os primeiros blocos logo depois da abolição da escravidão. Ali, cenas de sangue e de desordem não eram raras. Uma das razões, de resto, de a polícia em décadas subsequentes perseguir rodas de batuque e, logo depois, as de samba, identificando-as como "coisas de arruaceiros, de malandros e de perturbadores da ordem pública", segundo cronistas como João do Rio ou mesmo Jotaefegê, Edison Carneiro e Eneida.

A partir do comecinho da década de 30, os desfiles iniciais das escolas na Praça XI eram espontâneos e reuniam apenas algumas dezenas de pessoas. Em 1932, o jornal Mundo Esportivo patrocinou o primeiro desfile das então muito acanhadas agremiações. Foi um estopim. Porque já em 1933 - enquanto a era do rádio consolidava a efervescência dos sambas e das marchinhas carnavalescas - o desfile das escolas, ainda tímido, passou a ser patrocinado pelo jornal O Globo. Enfrentando quase duas dezenas de concorrentes, a Estação Primeira da Mangueira, de Cartola, de Carlos Cachaça e de outros bambas como José Espinguela, foi a campeã dos desfiles iniciais - inaugurando toda uma longa marcha de glórias. Até porque seu mito e sua história salpicam paixões irrefreáveis até os dias de hoje.

Mas - vale a pena repetir - quando as escolas começaram a aparecer, os desfiles de carnaval nas ruas eram então liderados pelas grandes sociedades, a que se seguiam os ranchos e os blocos. As escolas, em fase ascensional, embora desprezadas pela classe média carioca, receberam em 1934 um convite do jornal O Paiz que as elevaria ao pódio da excelência das organizações carnavalescas. Foi um desfile em homenagem ao Prefeito Pedro Ernesto, no Campo de Santana, local nobilíssimo dos festejos de rua ao longo de quase todo o século XIX.

Mais uma vez a Mangueira foi campeã. A Estação Primeira no mesmo ano assinaria - em posição de destaque - a novidade que assegurava a consolidação das escolas: o primeiro pacto entre elas, que tomou o nome de União das Escolas de Samba.

Como resultado desse passo de organização, o desfile das escolas no ano seguinte seria oficializado pela Prefeitura do Distrito Federal, se Ihes impondo um regulamento com normas que, a ferro e fogo, determinariam os rumos do desfile. Forjava-se, a par- 
tir daí, embora lentamente, o apogeu das escolas, que culminaria no Sambódromo Darcy Ribeiro.

Da corda clássica - que separava o público dos desfilantes nos tempos heróicos da Praça XI - até os camarotes de luxo de agora, foi árdua a caminhada. Das cores únicas (duas, quase sempre) com que cada escola desfilava, ao arco-íris de hoje, em que ao carnavalesco mais ousado é consentido empregar todas as cores e suas variações, a estética visual das escolas mudou tão drasticamente que muitos críticos já perfilam o termo "ditadura do visual", em detrimento da "dança no pé e canto no gogó".

Os ternos brancos bem comportados que os sambistas exibiam com orgulho nos anos 30 - que se antepunham ao despojamento do vestir diário, quando envergavam camisas listradas, calças de brim e chinelo "charlotte" - não deixavam de ser uma fantasia de doutor para ocupar pé e pescoço (tradução do malandrês: sapato fechado e gravata). Muito diferente das roupas de agora, com alegorias entupindo pés, mãos, cabeça. Mas, apesar das mudanças, ficaria mantida, felizmente, a inversão da estrutura social tão cara ao carnaval. E, é claro, tão necessária como descompressão para os sambistas, senhores absolutistas da organização de milhares de pessoas e titulares da beleza, da exceção, da originalidade, do comando naquela hora e pouco de desfile, toda uma magia em que se afoga um ano de miséria, de humilhação, de sensaboria...

Nas décadas de 30 e 40, o verde-rosa da Mangueira de Cartola e o azul-e-branco da Portela de Heitor dos Prazeres (o Mano Lino) e de Paulo da Portela (o Paulo Benjamim de Oliveira, que exerceu uma liderança historicamente robusta, injetando na organização do samba alguns traços da ideologia de Prestes, então em franca disputa com Getúlio) se alternavam absolutas na disputa do primeiro lugar, enquanto suas concorrentes (Unidos da Tijuca, Vizinha faladeira, Depois eu digo, ou Fique firme, para citar apenas algumas), nunca conquistaram nenhum campeonato, à exceção da primeira (Unidos da Tijuca), campeã solitária de 1936.

A primazia de Mangueira e Portela só seria quebrada pelo Império Serrano, fundado em 1947 (no sopé do Morro da Serrinha, Madureira) e que conquistaria sensacionalmente o tetracampeonato de 1948 até 1951, trazendo como jóias de sua Coroa Imperial verde-e-branca compositores como Mano Décio da Viola, Dona Ivone Lara (primeira mulher a fazer samba enredo, uma Chiquinha Gonzaga das escolas) ou Silas de Oliveira (autor de pelo menos dois dos mais saudados sambas de enredo de todos os tempos, Aquarela brasileira e Heróis da liberdade - que embute o verso genial: "Essa brisa que a juventude afaga / Essa chama que o ódio não apaga".

Os anos 40 e 50 foram um tempo em que as escolas absorveriam uma identidade formal bem mais definida que a do heroísmo da década de 30, agregando aqui ou acolá referências dos ranchos e, sobretudo, das grandes sociedades.

O pulo do gato, a ruptura, a grande novidade para as escolas, contudo, chegaria ao final dos anos 50. Quando o Brasil pulsava ao ritmo da Era JK. Quando Brasília se destacava como a ousadia urbanístico-arquitetônica mais flamejante do planeta. Quando a 
bossa nova descerraria cortinas musicais para novos músicos, jovens talentos universitários. Quando "uma câmara na mão e uma idéia na cabeça" faziam irromper a criatividade insolente do cinema novo. Quando, enfim, a esperança e a fé em destinos mais estimulantes sacudiam as consciências críticas dos brasileiros que não só pensavam o país, mas também as daqueles que queriam mudá-lo.

Eu diria que os eflúvios revolucionários dos anos JK chegariam às escolas de samba quando uma nova agremiação, a Acadêmicos do Salgueiro, fundada em 1953 e que patinava num quarto lugar obscuro durante desfiles a fio, resolveu inovar, contratando como carnavalescos Marie Louise e Dirceu Nery, um casal (ela suíça e ele pernambucano) de fundamentos acadêmicos, reconhecido com simpatia por boa parte do júri do Serviço de Turismo, órgão municipal que então organizava o desfile. Primeira providência dos Nery: acabar com a tradicional corda - que separava os desfilantes da platéia - e introduzir novos materiais, como a ráfia, a palha e outras fibras, até então não percebidos pelo olhar tradicionalista dos demais figurinistas das outras escolas. Segunda providência: inserir no ano seguinte no Salgueiro a liderança de Fernando Pamplona, seu amigo do júri de 1959 e que dera nota máxima à escola. Pamplona traria do Teatro Municipal jovens talentos como Arlindo Rodrigues e João Trinta e da Escola de Belas Artes alunos como Rosa Magalhães e Maria Augusta.

Essa injeção de novidades no Salgueiro acabou - como era mesmo de se esperar - por impor uma nova estética às escolas. Afinal, artistas plásticos jovens, audaciosos e de formação universitária, estavam comprometidos com novos caminhos e novos olhares. O começo dos anos 60 , portanto, decretaria a morte paulatina nas escolas de samba de uma estética suburbana e popular, e o nascimento irresistível de uma outra, a universitária e jovem. Os embates e os debates ante a estéticas novas, como sempre, deram panos para a manga e fizeram provocar discussões ideológicas.

Assim havia ocorrido com a chegada dos músicos da Bossa Nova, dos cineastas do Cinema Novo, da Capital Nova. O mesmo aconteceria com a adaptação dos novos padrões estético-conjunturais das Escolas, a partir das inovações do Salgueiro, cuja marca, aliás, já a autodefinia: "Nem melhor, nem pior, apenas uma escola diferente".

Enquanto o espetáculo prosseguia em seu ritmo inexorável para a futura consagração mundial, especialmente a partir do Sambódromo Darcy Ribeiro, boa parte da crítica não perdoava as mudanças, listando as perdas que basicamente eram (e podem ser, segundo eles, válidas até hoje):

1. a tirania dos carnavalescos agravaria a falta da identidade cultural fundamentada numa estética suburbana, de caráter artesanal e comunitário.

2. o desfile, cujos ingressos caríssimos passaram a ser disputados quase à tapa (ou apenas encontrados nos cambistas), ficaria apenas para os mais abastados. O povo mesmo estaria a ver navios. Ou a tevê, em suas casas.

3. a limitação do tempo do desfile, aliado ao aumento dos corpos estáveis de desfilantes, fez com que as escolas não mais evoluíssem tendo como essência a dança e o canto. A 
dança do samba seria substituída pela correria, instalada exatamente para cumprir a rigidez do horário implacável de uma hora e vinte minutos de desfile.

4. o andamento do samba estaria danosamente alterado, já que, para a evolução se enquadrar no limite do tempo, os sambas de enredo passaram a ser marchinhas simplificadas, quase sintéticas. E não mais sambas com letras compridas, a referenciar alongadamente todos os detalhes do tema apresentado.

5. alas inteiras de elementos estranhos à comunidade esfriariam a evolução das agremiações que as admitissem. Por outro lado, pagaria as caras fantasias quem pudesse, ou seja, os brancos mais endinheirados. Enquanto o negro pobre da comunidade ficaria alijado do desfile - que ele teria alimentado durante décadas.

6. fenômeno bem próximo também se notaria na plateia: os turistas e estrangeiros comprariam ingressos num nível prioritário - quase dois terços da lotação do Sambódromo -, o que igualmente ajudaria a esfriar as torcidas originais, que, em tempos idos, aclamavam suas escolas com paixão. E quase de graça.

7. interesses comerciais - em relação a direitos do CD da Liesa - presidiriam a escolha do samba de enredo, subtraindo-lhes a desejável espontaneidade.

\section{LAMÚRIAS, SAUDOSISMO, VERDADES, MENTIRAS?}

Como escrevia a cronista Eneida sobre aquilo que dizia com sua inesquecível voz rouca: "O tempo não anda pra trás. Amanhã deverá, sempre, ser um novo dia. Há que se adaptar a ele com paciência. E, se possível, respeitando-se as novidades que traz".

Em 1975, um novo choque estético chegaria: a Beija-Flor de Nilópolis, que, a partir de "Sonhar com rei dá leão" (que tratava, apropriadamente, do jogo do bicho, tão caro a boa parte dos patronos das agremiações) insere-se nos desfiles pra ficar. E fazer encabular a tradição - e os campeonatos - das escolas mais tradicionais e antigas.

A sequência de três vitórias em 1976, 77 e 78 - no momento da arrancada das escolas para seu apogeu de prestígio e de absorção por parte da classe média (que lhes fora indiferente, ou quase, nas décadas anteriores) - confirmam outras mudanças estéticas que fariam história.

À Beija-Flor credita-se a era definitiva do visual, privilegiando-se a riqueza e o luxo das fantasias, dos carros alegóricos, até mesmo de alas mais tradicionais e conservadoras como as das baianas ou mestre-sala/porta-bandeira, quando não da própria bateria.

João Jorge Trinta, o mago Joãozinho Trinta, resumiu outra etapa de reconfiguração estética, a partir da revolução empreendida em 1959 por seu mestre Fernando Pamplona, impondo uma frase definidora do que se pode considerar o gosto popular: "Quem gosta de miséria é intelectual, povo gosta é de luxo". A riqueza e o luxo a que João Trinta se refere esconderiam, na verdade, uma criatividade fortíssima, aliada a uma imaginação quase delirante em fazer reluzir coisas simples, só que convenientemente vestidas, apresentadas, propulsionadas à base do efeito. Ou do visual... 
E com isso ele não só ganharia para a Beija-Flor campeonatos. Mas imprimiria à Escola de Nilópolis, e a quase todas outras, suas marcas, suas referências, sua decantada genialidade em pensar com audácia. A tal ponto provocadoramente que ousou produzir (na Grande Rio) um destaque voador, redefinindo, uma vez mais, a estética do desfile. Que passou a admitir a partir de então referências e construções dos grandes shows da Broadway e da Disneyworld.

Se a Beija-Flor abriria tantas novidades com o pequeno e atrevido reformador que foi Joãozinho Trinta, a construção do Sambódromo em 1984, propulsionado por Darcy Ribeiro e projetado por Oscar Niemeyer, daria às escolas seu berço definitivo. Também a partir de 1984, enquanto o Sambódromo se punha de pé, as Escolas deram uma reviravolta em sua organização. Elas criaram uma Liga Independente das Escolas de Samba que profissionalizaria de vez o desfile, separando as escolas mais qualificadas, e as retirando da velha Associação das Escolas de Samba. Ficaram as escolas de samba agrupadas na Liesa (Liga Independente das Escolas de Samba).

O primeiro campeonato do Sambódromo, o de 1985, foi vencido pela Mangueira, que sinalizaria uma volta profética aos tempos idos e vividos. A velha Mangueira, a pioneira das escolas a ganhar o desfile inicial de 1932, arrebataria espetacularmente o campeonato no novo sambódromo sem se dispersar na Praça da Apoteose ao terminar o desfile. E o mais original - voltando, para deslumbramento da plateia, em direção à antiga Praça XI. Que desse modo retornaria simbolicamente a abrigar - décadas depois e no mesmo chão bem próximo ao Canal do Mangue - a mesma Mangueira que desde sempre marcou o território dos desfiles, dos sambas, do pioneirismo.

A partir do sucesso nacional que foi a criação do sambódromo no Rio, a cidade de São Paulo logo construiria o seu similar, com projeto do mesmo Oscar Niemeyer. Nas cercanias do Anhembi, o sambódromo paulistano viu crescer suas até então acanhadas Escolas de Samba. Agremiações que, fundadas dentro do mesmo modelo carioca, tinham origem em bairros populares da cidade e até a partir de torcidas de futebol. $\mathrm{O}$ arrojo e a força de vontade dos foliões paulistanos se embeberam do mesmíssimo elemento de essência que soprou o apogeu das escolas no Rio: a paixão, a tenacidade, a vontade de disputar e ganhar.

O desfile do Sambódromo do Anhembi logo ganharia transmissão exclusiva pela Rede Globo, que desde uma década antes já transmitia o show carioca. E São Paulo passou a ter também um superdesfile, em que, além da prata da casa com seus destaques, seus cantores, carnavalescos, participavam vez por outra estrelas do samba carioca, como Jamelão da Mangueira, talvez o maior cantor do desfile em todos os tempos - o termo "puxador" de samba ele sempre abominou.

Para dirigir e orientar as escolas paulistanas uma mesmíssima Liga Independente foi criada. Que a Liesa-SP organiza o desfile em duas noites (6a feira e sábado), com cuidado em não concorrer com o do Rio (domingo e 2a feira). Com autonomia bastante para poder dialogar com as autoridades. E fazer do desfile um espetáculo cotejado e disputado pela população, além de lucrativo - ao menos para as escolas campeãs. Que ostentam 
títulos até ontem desconhecidos no restante do país, mas hoje referências como Vai-Vai, Nenê de Vila Matilde, Rosas de Ouro, Unidos do Peruche, Gaviões da Fiel, Mocidade Alegre (campeã de 2007) e Império da Casa Verde (campeã de 2005 e 2006), isso para citar apenas alguns dos nomes que ganharam repercussão nacional.

Portanto, o desfile do Grupo Especial das Escolas de Samba do Rio e de São Paulo é um megaespetáculo que encanta o Brasil e o mundo. A cidade do Rio, especialmente ela que viu nascer essas agremiações de modo tão modesto, beneficia-se direta e indiretamente dos milhões de reais que o show faz movimentar.

A criação de milhares de empregos, ao longo de quase um ano todo de trabalhos, propulsiona gerações e gerações de profissionais autônomos ou artesãos e ainda artistas altamente especializados como escultores em papel, espuma ou gesso. Em torno das Escolas gravitam de pequenas indústrias até cooperativas de aderecistas, costureiras, bordadeiras, chapeleiros, além de batalhões de ferreiros, eletricistas, marceneiros etc.

Exausto, e muitas cervejas depois, terminei minha longa narrativa aos sociólogos da Sorbonne sobre a história das escolas. Logo testemunhei que os franceses bocejavam. De cansaço, de calor, de muita cerveja. Mas ainda puderam comentar, numa quase exclamação: "Só mesmo parafraseando Luís XIV: 'Après moi, le déluge' - após essa força opulenta das escolas de samba, o dilúvio...".

\section{NOTA}

10 presente artigo foi extraído do livro Meu carnaval Brasil da Editora Aprazível.

Ricardo Cravo Albin é escritor e jornalista. 
